\title{
CDX and iTraxx and their Relation to the Systemically Important Financial Institutions: Evidence from the 2008-2009 Financial Crisis
}

\begin{abstract}
This paper empirically investigates the linkages between the CDS index market and the equity returns of a sample of systemically important financial institutions (SIFIs). Both the 5year investment grade iTraxx Europe and the 5-year investment grade CDX North America indexes are adopted as a market consensus of the overall credit risk in the financial system. Through a multivariate VAR model using historical data, the investigation uncovers three key findings. First, the equity returns for all systematically important institutions are inversely associated to shocks in the CDS index market. Second, European institutions demonstrate a stronger connection with the iTraxx whilst the US institutions are more closely related to the CDX. Furthermore, volatility originating in the CDS index market is unambiguously transmitted to both the insurance and the banking sector. Third, US banks are most severely distressed by the volatility transmission mechanism whilst European insurers are least affected.
\end{abstract}

JEL Classification: G01, G15, G21, G24

Keywords: Credit default swap index, CDX, iTraxx, Systemically important financial institutions, Financial stability 


\section{Introduction}

Systemically important financial institutions (SIFIs) are financial institutions that are deemed systemically important to the economy in the sense that the failure of one of them could trigger a global financial crisis. Investment banks and insurance companies retaining large exposures to credit risk thus represent SIFIs.

Global institutions have demonstrated a continuous emphasis on managing credit risk. Although bonds and loans are still significant, the vast majority of credit risk now arises from derivative transactions. The shift is directly associated with the sharp growth in the over-thecounter (OTC) derivatives market which reached a colossal \$600 trillion at the end of 2010 . Outstanding notional for credit default swaps (CDSs) stood at \$30 trillion during the same period. However, through portfolio compression and clearing, the CDS market has recently contracted significantly from previous years.

In essence, the function of a CDS instrument is to transfer credit risk to increase the overall resilience of the financial sector. Credit risk transfer (CRT) increases diversification and thus transfer risk outside the banking system to other market investors - such as insurance companies and hedge funds. Through continuous trading, CDS spreads have significantly enhanced the transparency in assessing credit conditions for capital market stakeholders.

CDS indices are benchmarks for protecting investors owning bonds against default, and traders use them to speculate on changes in credit quality. There are currently two main families of CDS indices: CDX and iTraxx. These indices permit investors to take a position on a basket of credit entities rather than many single name CDS which can be significantly more costly. In fact, since these indices are standardised, the increased liquidity is likely to result in lower spreads being charged.

Although the overall welfare consequences of using derivatives are ambiguous, CDS played a vital role in the 2008-2009 financial crisis. The collapse of Lehman Brothers in September 2008 sent shockwaves around global markets. As a result, major European and US financial institutions came to the brink of failure. Those SIFIs with a greater exposure to US mortgage based securities required immediate rescuing, forcing governments to pump multitrillion bailouts into the banking sector to guarantee liabilities.

Our objective in this paper is to investigate the relation between changes in the level of the CDX and iTraxx indices and the equity prices of a group of SIFIs. In particular, we 
focus on a number of US as well as European-based systemically important banks and insurance companies whose failure can pose negative externalities to the financial system.

Two crucial questions that arise in investigating this potential linkage are: do fluctuations in the CDX and iTraxx indices play a significant role in transmitting shocks across the financial system? Does exist an empirical relationship between the dynamic patterns of the CDX and iTraxx indices and changes in the equity prices of SIFIs?

To address these questions, we develop tests that exploit the richness of our dataset and builds upon Yang et al. (2006) who employ generalized forecasts error variance decompositions (GVDs) to examine short-run dynamic causal linkages across the stock markets in Central and Eastern Europe, before and after the 1998 Russian financial crisis. Moreover, our paper is related to a growing body of empirical work featuring GVDs to measure systemic risk and financial connectedness for a set of the largest international financial institutions around the recent global credit crisis (e.g. Yang and Zhou (2013), Diebold and Yilmaz (2014)).

Hence, this article contributes to the literature by analysing a key aspect of the relationship between CDS indices prices and the equity value of a selected group SIFIs, and assesses the extent to which SIFIs' asset prices are driven by the volatility in the CDS index market. Our focus is on the evolution of spreads levels characterizing CDS indices markets.

Our analysis relies on a representative dataset of CDS prices spanning the entire financial crisis period (2007-2011). Although there exist CDS contracts of different maturities, the most liquid are the 5-year maturity. Therefore, this paper restricts itself to the daily 5-year CDS spreads.

The global financial system comprises thousands of banks and other financial institutions of various sizes and types. To better capture its complexity, this paper focuses on a defined group of the very largest institutions. Accordingly, the sample of banking organizations used here includes firms that have been identified by the Financial Stability Board (FSB) as globally systemically important financial institutions (G-SIFIs) ${ }^{1}$. In particular, in November 2011 the Financial Stability Board published an integrated set of policy measures to address the systemic and moral hazard risks associated with systemically important financial institutions (SIFIs). In that publication, the FSB has identified an initial group of G-SIFIs, namely 29 global systemically important banks (G-SIBs), using a

\footnotetext{
${ }^{1}$ G-SIFIs are defined by the FSB as "institutions of such size, market importance, and global interconnectedness that their distress or failure would cause significant dislocation in the global financial system and adverse economic consequences across a range of countries.
} 
methodology developed by the Basel Committee on Banking Supervision (BCBS). Furthermore, the International Association of Insurance Supervisors (IAIS) has developed a related initial assessment methodology to identify any insurers whose distress or disorderly failure, because of their size, complexity and interconnectedness, would cause significant disruption to the global financial system and economic activity. Any such insurers will be regarded as systemically important on a global basis. Global systemically important insurers (G-SIIs) are one class of G-SIFIs.

This allows us to adopt a homogeneous set of SIFIs.

The main reason we focus our analysis on this particular category of institutions is that the resilience and stability of these institutions is of particular concern to central banks and financial regulators ${ }^{2}$. The extent to which regulators understand the stability aspects of credit risk transfer and the effects of complex financial products in financial markets is surely an important one, and has been the subject of recent research by - among others - Allen and Carletti (2006), Allen and Gale (2004), Brunnermeier (2008), Duffie (2008), Gorton (2009) and Longstaff (2010). Consequently, knowledge of the extent to which SIFIs are interrelated - and exposed -to other financial markets is important for the assessment of risks to financial stability emanating from these institutions.

Our empirical approach proceeds in four steps.

First, we study the nature of systemic credit risk using CDS spreads for the US CDX and the Europe iTraxx indices, since CDS premia are generally regarded as a critical measure of market confidence. Second, we examine the issue of correlations between the indices and an institution's equity value. In this study, banking and insurance equity prices are standard measurement proxies for financial stability under the assumption that the viability of such organisations plays a crucial role in maintaining a healthy economy. A Vector Autoregressive (VAR) framework is thus utilised to analyse price changes, following shocks in the CDS market. Third, we employ generalized forecast variance decompositions to establish lead-lag causal relationships between the CDX and iTraxx indices and the group of SIFIs. Fourth, we estimate the influence that volatility in the CDS market transmits to the volatility of the SIFIs' equity prices. The volatility clustering assumptions suggest the magnitude of asset returns appear in clusters. Large returns (in either direction) are expected to follow large

\footnotetext{
${ }^{2}$ See the recent regulatory proposals by the Global Financial Stability Board and the Basel Committee on Banking Supervision.
} 
returns. To measure volatility transmission effects, we specify and estimate a generalised autoregressive conditional heteroschedastic $(\mathrm{GARCH})$ model.

A number of important empirical results emerge from this analysis.

First, we uncover a negative correlation between the movements of the CDX and iTraxx indices and the equity returns for all the 30 SIFIs. Most notably, the CDX index possesses the greatest explanatory power in the variation of the equity returns of all the SIFIs.

Second, volatilities of the returns of the CDX index tend to be transmitted to the volatilities of equity returns of the financial institutions. Both the US and the European SIFIs are significantly affected.

Third, our empirical evidence from the Granger causality test reveals a strong interconnectivity between the CDS indices. The five year investment grade CDX appears as the dominant index since not only contributes to pricing discovery in the five year investment grade iTraxx Europe but also leads this process. Hence, although financial markets are naturally inclined to follow a 'random walk', this suggests that arbitrage opportunities may exist for market participants. However, these are likely to disappear very rapidly as efficient markets do adjust spreads back to equilibrium.

Fourth, quite strikingly, our empirical evidence uncovers a strong association of negative sign between the geographical location of a SIFI and a shock in the corresponding CDS index market. Accordingly, the iTraxx exhibits a more dominant impact on all European institutions selected in the study, whilst the CDX demonstrates a larger impact on the US institutions. These results are somewhat surprising since they seem to tell us that globalisation has a neutral impact on international diversification activities. However, remarkably a larger 'non-dominant' index impact on the insurers suggests the insurance sector is diversifying its activities across the Atlantic at a faster pace than the banking sector.

The remainder of this paper proceeds as follows. Section 2 describes the data. Section 3 discusses the econometric methodology. The results are presented and interpreted in Section 4. Section 5 summarises the main findings and offers concluding remarks. 


\section{Dataset}

\subsection{Equity Returns}

Equity returns are utilised in this study as a measure of financial stability, since the stock market performance of systematically important institutions can severely disrupt the financial system. For the purpose of consistency, equity returns are displayed in a single US dollar format for each participating institution.

This research is centred on thirty SIFIs, all of whom are heavily exposed to credit sensitive instruments. In order to further enhance the analysis, institutions are evenly split into two subgroups, namely banks and insurance companies. A large data range and sectoral segregation permit a comprehensive analysis to determine underlying issues transpiring in the financial system.

Daily returns provide a larger dataset, and capture additional shocks in comparison to an investigation comprising of data with a lower frequency. Furthermore, the study maintains an adequate amount of consistency through obtaining returns at close price. Returns are subsequently filtered into the two independent work files to remove existing anomalies.

Post filtering, exactly 1414 daily observations are included in the bank and index data for the selected time period. In contrast, 1501 daily returns are observed between the insurance companies and index data.

\subsection{Bank Data}

Banks are highly diverse financial intermediaries, dealing in a range of financial activities such as underwriting and brokerage. A group of fifteen global investment banks are included in the study (see Table 1). As stated previously, the selection criteria are based upon the 'too big to fail' FSB classification and institutions with a large exposure to credit risk through long positions in CDs.

\section{INSERT TABLE 1 HERE}

Banks retaining large positions in CDs are revealed to hold a larger proportion of nonperforming loans, therefore signalling neglected resources when completing essential 
credit checks. Furthermore, the lower performing loans entailed additional expense in resolving bad and doubtful debts. The 'short-termism' views of the fifteen selected banks thus encountered significantly higher adverse effects during the subprime meltdown, in comparison to their more prudent counterparts.

\subsection{Insurance Company Data}

We also collect equity prices data for fifteen of the world's largest insurance companies. Specifically, we consider seven insurers identified by the IAIS as SIFIs. In addition to this sub-group, we also include eight global insurers acting as key counterparties in most CDs transactions (see Table 2).

\section{INSERT TABLE 2 HERE}

\subsection{CDS Index Data}

This study includes daily midmarket spreads for the two most liquid CDS indices: the investment grade North American CDX and iTraxx Europe with reference issues ranked senior and CDS maturities of 5 years. Pricing is freely available on a daily basis since transparency is an important advantage of utilising CDS indices.

The 5-year Markit CDX North America comprises of 125 Investment grade issuers, each covering equal principle amounts of debt. Since the Markit CDX index is accepted as a market consensus of the overall credit risk, spread returns are adopted to serve as the benchmark for market confidence. Higher investment grade spreads therefore suggest low market confidence and thus a weaker economy. The notional amounts for the CDS indices data are all specified in dollars.

The 5-year iTraxx Europe main index is composed of 125 of the most liquid investment grade credits. Similar to the CDX, returns in the iTraxx index encapsulates credit risk for a representative sample of European corporates. This implies correlations are likely to exist between both indices.

Institutional equity data is gathered from Thomson Reuters DataStream3. CDX and iTraxx prices come from Bloomberg which collects CDS market quotation data from industry sources. The sample covers the period from January 2005 to June 2011.

\footnotetext{
${ }^{3}$ Primary financial data (filtered and unfiltered) is available upon request.
} 


\section{INSERT TABLE 3 HERE}

\section{Methodology}

In this study, we provide an entirely new perspective on the interaction between the CDS index market and the risk profile of a financial institution. The risk profile of the financial institution is determined by the value and volatility of equity. Decreasing equity values and increasing volatility contribute to the institution's fragility. When developments occur simultaneously for a number of institutions following the same 'credit market' shock systemic risk will rise causing a marked deterioration of financial stability.

This section briefly outlines the econometric model employed to examine the linkages between CDS indices and SIFIs.

\subsection{Assessing the Impact of the CDS Indices on SIFIs Equity Value}

In the first step, we use a VAR model to test the possible impact of CDS indices on the market valuation of each individual financial institution.

The new macroeconomic framework provided by Sims (1992) captures the evolution of endogenous variables and independencies between multiple time series as a natural generalisation of univariate models. Each variable is in turn explained by its own lagged values, in addition to recent and historic data (Stock and Watson, (2007)). Furthermore, VAR models do not require the estimation of endogenous and exogenous variables since all variables are treated as endogenous.

\section{INSERT FIGURE 1 HERE}

To identify the impact on other endogenous variables in the structure of the VAR, namely the institutions equity return, we compute generalised forecast error variance decompositions (GVDs) between the equity and index returns. The advantage of considering this testing procedure is that shocks are not depending on variable ordering. Note that in general shocks will gradually fade away only in a stable system. Hence, to ensure estimation accuracy we employ a time horizon of 10 days-ahead. 
GVDs are computed and compared to determine which index has a larger impact on individual institutions in the VAR model.

A VAR framework constitutes a convenient framework to assess the interrelationships within a system of variables when the imposition of strong a-priori restrictive assumptions cannot be derived by economic theory.

Assume that the interconnections between the variables of interest can be depicted by the structural linear system that relates the vector of variables $Y$ in the system:

$$
A_{0} Y_{t}=A_{1}(L) Y_{t-1}+\varepsilon_{t} \quad \mathrm{t}=1, \ldots, \mathrm{T}(1)
$$

The vector of structural disturbances $(\mathrm{n} \times 1) \varepsilon_{t}$ consists of independent random variables with zero mean stochastic elements with diagonal covariance matrix $E\left(\varepsilon_{t} \varepsilon_{t}^{\prime}\right)=\Sigma$. The contemporaneous relationship between the variables is depicted by $A_{0}$, whose diagonal elements are normalised to the value of unity and $A_{1}(L)$ is a matrix polynomial in the lag operator.

Associated with the structural form, the 'observed' reduced form of the model given by (1) can be represented by a VAR model of the form:

$$
Y_{t}=B(L) Y_{t-1}+e_{t}
$$

The covariance matrix of the reduced form disturbances $e$ is given by: $E\left(e_{t} e_{t}^{\prime}\right)=\Omega$. From (1) and (2) is obvious that the structural errors and the reduced form disturbances are related by the following equation:

$$
\varepsilon_{t}=A_{o}^{-1} e_{t}
$$

To recover the parameters of interest $A_{0}$ and $\Sigma$ from the estimation of (2) the imposition of parameter restrictions on $\Omega$ is required. This matrix is symmetric with $\left(n^{2}+1\right) / 2$ distinct elements requiring the imposition of restrictions. The necessary condition for exact identification of the structural parameters is that the number of parameters in $A_{0}$ and $\Sigma$ is the same as the number of non-zero elements in $\Omega$. The main advantage of employing the SVAR methodology is the evaluation of the system responses to structural 
shocks using the reduced form VAR model and a relatively small number of exclusion restrictions. Writing model (2) in its equivalent moving-average form we obtain:

$$
Y_{t}=C(L) e_{t}=\mathrm{C}_{o} \mathrm{e}_{t}+\mathrm{C}_{1} \mathrm{e}_{t-1}+\ldots
$$

The MA coefficients are related to the reduced form parameters via the recursion:

$$
C_{0}=I, C_{1}=B_{1}, C_{2}=B_{1} C_{1}+B_{2}
$$

and their sum is given by:

$$
C^{*}=\sum_{i=0}^{\infty} C_{i}=\left[I-\sum_{i=1}^{p} B_{i}\right]^{-1}
$$

Simple exclusion restrictions can be imposed that guarantee exact identification. The most common assumption is that $\Sigma$ is a diagonal matrix, the covariance of the structural shocks is zero. Further exclusion restrictions can be imposed on $A_{0}$, and subsequently on the structure of $\Omega$ that allow to identify the estimated system. The use of such restrictions has been questioned by Chari, Kehoe and McGrattan (2005) who argue that restrictions should originate from the underlying behavioural model that generates the VAR, and they are not to be used for empirical convenience. Sims (1980) suggested that simple short run exclusion restrictions can be imposed in the presence of a natural timing sequence in the manner the shocks that affect the system. Long-run restrictions motivated by the description of equilibrium derived from economic theory can be used to provide identifying restrictions. By postulating $A_{0}$ as a lower triangular the system assumes a recursive structure and this along with the restricted nature of $\Sigma$ provides for the exact identification of the unrestricted VAR.

Under such conditions a well-defined two-step procedure can be used to extract estimates of the structural parameters from the estimation of the reduced form.

The algorithm requires that the estimate $\hat{\Omega}$ is obtained from (2) and the structural model coefficients are obtained from maximizing the likelihood function that obtains consistent and efficient estimates of the parameters of interest. 


$$
l\left(A_{0}, \Sigma\right)=-\frac{T n}{2} \log (2 \pi)+\frac{T}{2} \log \left|A_{0}\right|^{2}-\frac{T}{2} \log |\Sigma|-\frac{T}{2} \operatorname{tr}\left[\left(A_{0}^{\prime} \Sigma^{-1} A_{0}\right) \hat{\Omega}\right](7)
$$

The variance of each element of $Y_{t}$ can be decomposed into components due to each element of $\varepsilon_{t}$ for various horizons.

$$
\operatorname{Var}_{t}\left(Y_{t+j}\right)=\sum_{i=0}^{j-1}\left\{\left(C_{i} A_{0}^{-1}\right) \Sigma\left(C_{i} A_{0}^{-1}\right)^{\prime}\right\}
$$

In addition the dynamic response of each element to a shock is traced via the computation of the following generalized variance decomposition for the forecasting error:

$$
\theta_{i j}^{c}(n)=\frac{\sigma_{i i}^{-1} \sum_{l=0}^{n}\left(e_{i}^{\prime} A_{l} \sum e_{j}\right)^{2}}{\sum_{l=0}^{n} e_{i}^{\prime} A_{l} \sum A_{l}^{\prime} e_{i}}
$$

Where $\sigma_{i i}$ is the $i i t h$ element of the residual variance-covariance matrix $\Sigma$, and $e_{t}$ is a selection vector, with the ith cohort equal to 1 and all the other cohorts equal to 0 . Therefore, $c(n)_{i j} \theta$ measures the contribution of the jth-innovation to the variance of the total $n$-step ahead forecasting error for the variable $Y_{i t}$.

In the VAR, variance decomposition separates the variation in an endogenous variable into the component shocks to the VAR. Thus, the variance decomposition provides information about the relative importance of each random innovation in affecting the variables in the VAR.

The GVD tells us the proportion of the movements in a sequence due to its "own" shocks versus shocks to the other variable. Unlike the orthogonalized variance decomposition and impulse response functions obtained using the Choleskey factorization, the generalized variance decomposition and impulse response functions are unique solution and invariant to the ordering of the variables in the VAR (Koop et al. 1996; and Pesaran and Shin, 1998).

Although simple, the VAR framework provides a useful way of determining the institution's equity prices responses to CDS indices shocks. However, limitations of VAR analysis essentially require discussion to minimise any negative reflection on the significance of the results. First, VAR usually requires a large number of parameters, even when the lag 
order is relatively low. The majority of institutions display a lag of order two. By adopting the parameter formula discussed earlier, a three variable two lag model requires the estimation of 30 parameters.

When positive shocks to either or both of the indices impact negatively on equity returns, the value of the equity declines resulting in increased institutional fragility due to the progressive reduction to the value of equity capital.

We estimate 30 three-equations VAR systems of the form: $\left\{d \log (c d x)_{t}, d \log (i t r x)_{t}, r_{i, t}\right\}_{t=1}^{T}$ where $d \log ($.$) denotes the continuously compounded returns$ of CDX and iTraxx indices whilst $r_{i, t}$ is the return of the SIFI $(i)$. In the absence of a fully specified behavioural model, the adoption of this methodology allows to establish the existence and the nature of a statistical causal relationship between the evolution of the indices of the credit derivatives markets and the equity returns of SIFIs. Our interest is the exploration for such impact rather than the acquisition of estimates of the behavioural structural parameters. What is of importance in this case is the identification of shocks as 'structural'.

Each VAR test involves the estimation using three variables: the financial institution equity return, the CDX index premia and the iTraxx index premia.

$$
\left(R_{i, t}, R \log (C D X)_{t}, R \log (i \operatorname{Trax} x)_{t}\right)_{t=1}^{T}
$$

Where $R_{i, t}$ denotes the return of institution $i$, and $R \log ()$ represents the continuous compounded return for both CDX and iTraxx indices - frequently referred to as the 'shock variables'.

The VAR model attempts to establish causal connections among equity prices and index returns, whilst avoiding the requisite to specify exogenous and endogenous variables. This suggests the model can verify the direction of the relationship to determine whether shocks in the institutions follow the index or vice versa. A key objective of the study is also to provide an intuitive economic interpretation of the relationships between these three variables.

\subsection{Assessing the Impact of the CDS Indices on SIFIs Equity Volatility}


As discussed earlier in the paper, we use a univariate GARCH $(1,1)$ model to assess the volatility in the CDS index markets and its transmission into the banking and insurance sector.

Spillovers effects do increase equity risk and as such significantly weaken financial stability, since individual financial distress will propagate to other financial institutions. Furthermore, excessive volatility in CDS indices may destabilize a large number of key SIFIs leading to disruptive consequences. Estimating and understanding the transmission mechanism is therefore a major objective of the study.

Since the variance in the error term $\mathbf{U}$ is unlikely to remain constant, it seems natural to adopt GARCH modelling to parameterise the returns. These models take into consideration volatility clustering, visible in both the $\mathrm{CDX}$ and iTraxx data. Furthermore, volatility is also assumed to be autocorrelated in equity returns. Therefore, one can assume the conditional variance of the error term as being dependent on the value of the previous term.

The multivariate GARCH model utilises the three key components of the analysis with the institutions equity return being treated as the dependent variable. Since a GARCH $(1,1)$ model is adopted, a one period lag exists in both the conditional volatility and innovation term. Therefore, the indices and the institutions returns are included in the model through a one period lag.

The procedure to estimate the volatility transmission proceeds as follows. The CDX and iTraxx indices are utilised to estimate a VAR-MV (GARCH) system, thereby acting as 'regressors' in the conditional volatility equation. This equation also comprises of each individual institution's equity price and employs a univariate GARCH model to estimate the conditional variance:

$$
\begin{gathered}
y_{i, t}=F_{t-j}+u_{i, t} \\
u_{i, t} \sim N\left(0, h_{i, t}\right) \\
h_{i, t}=\alpha_{0}+\sum_{q}^{Q} \alpha_{1}\left(u_{t-q}\right)^{2}+\sum_{p}^{P} \beta_{p} h_{i, t-p}+y_{1} h_{t}^{C D X}+y_{2} h_{t}^{i T r a x x}
\end{gathered}
$$

Where $y$ represents the institutions equity return as the dependent variable and $F$ denotes the determinants of the return. $\boldsymbol{h}_{t}^{C D X}$ and $\boldsymbol{h}_{\boldsymbol{t}}^{\text {iTraxx }}$ represent the varying conditional variance of the CDX and iTraxx respectively.

An increase in conditional volatility in the dependent equity variance equation would signal the impact of the CDS market index on the SIFI share prices. Hence, the index may 
have a direct contribution to a SIFIs equity return when the index conditional volatility enters the equity variance equation with a positive sign. According to Brooks (2008), the sum of the GARCH coefficients gives a clear indication to the persistence of the shocks. Thus, a large sum of coefficients implies a large index movement in either direction. GARCH coefficients $\alpha_{0}, \alpha_{1}$ and $\beta$ are, therefore, summed to evaluate volatility shocks from the indices to the equity value of the institution.

It is worth pointing out that the GARCH model adopted in this paper is unable to distinguish the asymmetric consequences of positive and negative innovations. However, since the model's goal is to essentially uncover a causal relationship rather than forecast future volatility, leverage effects can be somewhat ignored.

\section{Empirical Results and Discussion}

In this section, we conduct empirical tests with the data specified in Section 2 and the model described in Section 3. Results are then analysed and interpreted to draw conclusions.

To determine how observed short-run fluctuations of the CDS indices influence on short-run changes in SIFIs equity returns, we estimate our VAR-MV (GARCH) presented in the previous section ${ }^{4}$.

\subsection{VAR Results}

In this section, we proceed to estimate our VAR model to investigate the validity of our assumption. All the results pertain to our sample of 30 institutions. Specifically, two VARs are estimated separately for 15 banking SIFIs and 15 insurance sector SIFIs. Next, we proceed with a combined analysis of the two sectors. Each individual institution's equity return is combined to the CDS index spread return to form the three variables adopted in the VAR analysis (see Equation 10).

\subsubsection{VAR Estimates in the Banking Sector}

VAR models capture the evolution between bank equity returns and CDS markets. One standard deviation impulses are passed through the VAR systems to examine the

\footnotetext{
${ }^{4}$ Causality, Variance Decomposition, VAR and GARCH statistics are available upon request.
} 
reactions of the endogenous variables. In the case of this study, bank equity return is the response variable, and the first period's impulse is included. Furthermore, only in the case of stable systems shocks gradually fade away. The results show merely the first period is significant for the all systematically important banks and therefore, we exclude impulses over subsequent points in time. Through monitoring the effects of shocks in the first period, we find that the bank equity returns are negatively correlated to both iTraxx and CDX indices ${ }^{5}$.

We focus our discussion on the GVD analysis.

Variance decompositions show how much of the forecast error variance in a variable is explained by shocks to the variable itself and other variables. In this paper, this approach is employed to investigate the contribution made by the CDX and iTarxx indices towards the equity returns variance of the SIFIs. Table 4 reports the results of the two CDS indices contribution to the equity returns of the 15 G-SIFIs after 10 periods (t-stat).

Taken together, our estimates indicate that the explanatory power of the CDX is mostly significant for the US group of G-SIFIs. The CDX market factor is marginally significant, explaining in each case, only $6.32-8.92 \%$ of the variation (Lehman Brothers shows the highest CDX variance contribution, $12.68 \%)^{6}$. A key point to note is the marked symmetry in the LCFIs equity variance contribution of CDX and iTraxx. The iTraxx influence is essentially close to zero for all the US banks within the peer group.

By contrast, the iTraxx contribution is relatively more important for all the European LCFIs (Barclays, Royal Bank of Scotland, BNP Paribas, Societe Generale and UBS) where over $10 \%$ of their variation is explained by the iTraxx (it ranges from $14.45 \%$ (Barclays) to $11.55 \%, \mathrm{UBS})$.

\section{INSERT TABLE 4 HERE}

Both indices demonstrate a significant negative correlation to bank equity returns. An increase in CDX or iTraxx spreads drive bank equity returns in the opposite direction, in turn impacting on financial stability. In absolute terms, European institutions suffer greater return reductions with the largest impact for Barclays, BNP Paribas, RBS and Société Générale. As

\footnotetext{
${ }^{5}$ Impulse response functions estimates are available upon request.

${ }^{6}$ As expected, the explained variation estimates are higher than the original data series variance. This is mainly due to the dramatic jump in market volatility occurred throughout the 2008 . The initial data series results are available on request.
} 
can be seen from Table 4, this effect is relatively more important for all the American banking institutions.

A number of interesting patterns can be seen in these results.

Table 4 clearly shows that the $\mathrm{CDX}$ tranche index is the main driver contributing to the variation of equity returns among all the American banks. Similarly, all European banks equity returns exhibit a stronger relationship to the iTraxx index.

Remarkably, our empirical evidence shows that the enhanced spillover effects' affecting European banks can be attributed primarily to the composition and risk profile of banks' balance sheets. According to DeMarzo (2005) the rationale behind the rapid growth of the ABS and MBS markets should be found in traditional asymmetric information problems, which made pooling and tranching assets a highly profitable business. Since modern portfolio theory states unsystematic risk is reduced through diversifying operations, banks more influenced by CDS markets are likely to have over-exposed themselves to credit related instruments, thus increasing the systematic risk factor within the financial system. A large number of systematically important banks came to the brink of a collapse when in late 2008, following the collapse of Lehman Brothers, both the CDX and the iTraxx indices spreads dramatically shoot up. Banks thus required immediate emergency government intervention and multitrillion bailouts packages to prop up their capital adequacy ratios. A possible takeaway from these results is that widening CDS index spreads represent a prominent early warning signal for financial stability policies.

On the other hand, globally active banks such as Goldman Sachs and HSBC are affected the least. In fact, these institutions emerged from the crisis in a stronger position than their counterparts suggesting that, in such circumstances, a profitable strategy was to 'lean against the wave'. Furthermore, it is important to note that the combined impulses provide a clear picture on the overall impact during the financial crisis. Both Goldman Sachs and HSBC again emerge as the least likely to threaten global financial stability when the CDS market spreads increase (see Table 4). In contrast, the UK institutions, namely Barclays and RBS, are severely exposed in the face of a global economy downturn and when CDS index spreads are increasing.

These results relate to the contemporaneous paper by Yang and Zhou (2011) who find a particularly strong influence of Lehman Brothers on Bear Stearns (29-33\%), Goldman Sachs (35-42\%), Merrill Lynch (21-26\%), Wachovia (22-27\%), Citigroup (9-12\%) and JP 
Morgan (10\%) at all horizons ${ }^{7}$. These results also complement Diebold and Yilmaz (2014) who empirically document that, on the announcement of its bankruptcy (15 September 2008), Lehman Brothers was the most influential in terms of volatility connectedness (6\%).

By contrast and somewhat interestingly, these results deviate from Calice and Ioannidis (2012) who find that the transmission impact of the CDX is significantly larger for banks domiciled in continental Europe and UK as opposed to the US.

\subsubsection{VAR Estimates in the Insurance Sector}

We turn now our analysis to the internationally active SIFIs from the insurance sector. We perform VAR analysis to uncover the empirical relationship between the returns of each individual insurance firm and the returns of the CDS indices. We employ GVDs to estimate the relative impact of $\mathrm{CDX}$ and iTraxx indices on the endogenous variables. The systematically insurance companies equity returns are thus the response variables in the system (see Table 5). We can clearly see that shocks gradually disappear within ten periods for all the institutions.

\section{INSERT TABLE 5 HERE}

Taken together, the estimated VAR results show that shocks originating from the CDX and the iTraxx have a significant impact on the institutions stock returns. All the GVDs clearly document a significant contribution of the returns of the index series to the equity returns of the global insurance companies.

Note that all of the European institutions are essentially sensitive to the iTraxx CDS market. ING, AEGON, AXA and Prudential display the strongest response among the insurers, with all being significantly affected by shocks in the iTraxx index.

The Netherlands-based institutions appear the most vulnerable to shocks in the CDS index market. Noteworthy, this result is confirmed by the $€ 10$ billion Dutch government bailout of ING towards the end of 2008 as CDS indices premia dramatically widened.

AIG and MetLife are the American institutions most severely influenced by shocks to the CDS indices. AIG faced the most difficult financial crisis in its history when a series of

\footnotetext{
${ }^{7}$.No other US financial institutions exhibit such an extensive and significant role of credit risk information spillovers. Thus suggests that the decision not to bail out Lehman Brothers was probably a serious mistake and certainly worsened the global credit crisis.
} 
events unfolded in late 2008, eventually leading the Federal Reserve to engineer an $\$ 85$ billion rescue package, making it the largest government bailout of a private company in US history. The results for MetLife are somewhat surprising due to the low profile maintained by the insurer during the crisis. Nevertheless, a possible reason for this is the downgrading of MetLife's credit rating to A+ by Standard and Poor's. In contrast to the AA+ credit rating in early 2007, the downgrade reveals a negative impact on the insurer's financial position.

Interestingly, when combining the GVDs estimates for both the iTraxx and the CDX indices, we can observe three common patterns among individual insurers during the global financial crisis. First, when the CDS indices spreads peaked in late 2008, equity returns for ING, AEGON and AXA deteriorated more significantly than the reinsurance companies. Second, trends in location are less distinguishable in the insurance sector. Third, the overall impact amongst insurers is significantly higher than the in banking sector. Therefore, these findings lend support to the notion that the insurance sector is more segregated in terms of CDs trading.

\subsubsection{Combined VAR Estimates in the Financial Sector}

The estimated VARs uncover a significant linkage between movements in CDS index spreads and institutions equity returns for all the SIFIs. Over the six and a half year sample period, all the US-based institutions appear more heavily influenced the CDX index. Similarly, all the institutions based in Europe are more significantly affected by the iTraxx index. Thus quite remarkably, our empirical evidence uncovers a strong association between the geographical location of a financial institution and the corresponding US or European CDS index market.

All in all, our estimates illustrate a strong link between the CDX index and the US SIFIs. In particular, they highlight the importance of the long-run impact of the North American investment-grade credit index on the banks equity performance.

Notably, our findings indicate that the SIFIs from the insurance sector are more prone to shocks in the CDS market, with ING and Berkshire Hathaway being subject to the largest and smallest impacts, respectively. The results therefore imply that the insurance sector is much more segregated in CDs trading activity since derivative transactions are considered 'non-core' activities in the insurance sector (see, Cummins and Weiss (2010).

As shown in Table 5, despite being the largest shareholder in Wells Fargo, Berkshire Hathaway appears as the most stable insurer in terms of resilience to shocks originating from 
the CDS index. HSBC exhibits a similar low statistic in contrast to other banking institutions. As such, it seems reasonable to assume that Berkshire Hathaway and HSBC are least likely to endure instability as CDS markets develop. However, it is important to note that counterparty risk is likely to rise for these institutions in times of crisis. In turn, significant increases in counterparty risk will have the effect of reducing credit supply as seen in the period immediately preceding the 2007 subprime crisis.

The impact of the 'non-dominant' index on the banking and insurance sectors provide direct evidence about the degree of diversification into global CDS intermediation businesses. As a general pattern, we find that the insurance sector SIFIs exhibit greater international diversification in comparison to the banking sector. We derive our results by using the CDS globalisation ratio:

\section{CDS globalisation ratio $=$ Non-Dominant Index $/$ Dominant Index}

Note that a value close to one suggests a more active engagement of a SIFI in credit related activities ${ }^{8}$. Taken together, our results illustrate that the banking SIFIs in general lag behind the insurance SIFIs as for the level of global CDS diversification (see Figure 2). In accordance to portfolio theory, insurers are regarded as less exposed to a domestic financial crisis, since only a fraction of their 'non core' business is affected. Banks, on the other hand (with the exception of Deutsche Bank), are in a predominantly weaker position and, therefore, are likely to be affected more severely during times of high volatility. Banking institutions thus pose potentially a greater threat to financial stability as opposed to the more globally CDS diversified SIFIs insurers.

\section{INSERT FIGURE 2 HERE}

\subsection{Volatility Transmission Results}

In this section, we examine the impact of the structured credit market volatility on the SIFIs equity returns using a univariate GARCH model. Furthermore, as discussed earlier, we obtain the estimates of the conditional volatilities of the two indices from a multivariate

\footnotetext{
${ }^{8}$ The results are available upon request.
} 
GARCH $(1,1)$ model using a Diagonal BEEK specification ${ }^{9}$. The estimated GARCH coefficients are presented in accordance with equation (11). Recall from earlier discussion that a larger sum of coefficients implies that the institutions variance of returns will be higher for an extended period, under conditions of elevated volatility in the CDS markets. In other words, when the lagged conditional variance is closer to unity (exactly one), prolonged volatility clusters are likely to appear.

\subsubsection{GARCH Estimates in the Banking Sector}

The significance of the GARCH coefficients are statistically computed and compared to determine the transmission of volatility effects from CDS index markets into the banking institutions equity prices (see Table 6).

\section{INSERT TABLE 6 HERE}

Our findings above indicate that the sums of the lagged coefficient are always close to one, revealing a large impact on the dependent variable. This suggests a persistent transmission of volatility between the CDX and iTraxx indices and the banks equity prices. Excessive volatility in the CDS market can lead to considerable increases in volatility in the banking sector thereby exacerbating the fragility of the financial sector. Consistent with the definition of financial stability proposed by Cihak (2007) and Segoviano and Goodhart $(2009)^{10}$, the probability of possible shocks spreading throughout the financial system are therefore extremely significant for all the systematically important banks.

Another important result from Table 6 is the positioning of US institutions. The empirical results for Lehman Brothers, Citigroup and Goldman Sachs suggest the transmission impact is larger for banks situated in the US, as opposed to banks based in Europe. Consequently, the US institutions are prone to larger systematic risk since large swings in either direction in the CDS index market significantly affect banks share prices.

The coefficients from the GARCH estimates imply that, in the long run, increases in CDS market volatility are associated with a substantial increase in the SIFIs equity risk. Despite volatility impacts remaining at low levels for Société Générale and Credit Suisse, the

\footnotetext{
${ }^{9}$ The results are available on request.

${ }^{10}$ Both papers posit that a good measure of systemic stability has to incorporate two fundamental components: the probability of an individual financial institution defaulting, and the probability and speed of possible shocks spreading throughout industry.
} 
coefficients are nonetheless significantly high. All in all, our findings show that amplified volatility in the CDS market render the whole banking sector systematically more vulnerable to shocks.

\subsubsection{GARCH Estimates in the Insurance Sector}

GARCH coefficients are again computed for the insurance companies to better understand volatility transmission effects in the insurance sector (see Table 7).

\section{INSERT TABLE 7 HERE}

Since the coefficients are adjacent to 'unity', volatility transmissions are highly significant in the insurance sector. Interestingly, we can also observe a significant negative relationship between the volatility of the CDS index market and the stock return volatility of our 15 SIFIs insurance sample. Our empirical evidence suggests that an unexpected shock in the CDX or iTraxx can increase the conditional variance in the insurer's equity price.

With the sole exception of Berkshire Hathaway, estimations for the US insurance companies are generally higher than their European counterparts. Hence, the equity variance stands high for a protracted period when CDS indices exhibit high levels of volatility.

As it is shown by the large range of summed coefficients of the VAR analysis, the impact on the insurance sector appears far more differentiated. Furthermore, this result is even pronounced during the 2008 crisis. Interestingly, we can see that AIG, Manulife and Assicurazioni Generali are significantly more sensitive to shocks in the CDS index market.

\subsubsection{Volatility Impact on the Combined Financial Sector}

The estimated coefficients are significant in both the banking and insurance sector. However, from Figure 3 we can see that banking institutions are subject to larger impacts than the insurance companies.

\section{INSERT FIGURE 3}

We can achieve a better understanding of the factors behind the greater sensitivity of the banks equity prices to volatility shocks in the CDS index markets through a closer 
inspection into their core operations over the financial crisis period. Financial intermediaries retained the major proportion of credit losses arising from subprime mortgage back securities, even though the main objective was to package and disperse credit risk to investors more financially able to absorb losses. Choudhary and Landyut (2010) argue that banking is a business based on confidence and enhanced uncertainty will always lead customers to unwind positions and withdraw deposits on a large scale. Since only a fraction of liabilities are held in bank reserves, deteriorating confidence levels are often a market signal for instability. Arguably, the results in Figure 3 could reflect to some extent the critical role of confidence, since swings in volatility are transmitted more severely into the banking sector.

Another credible argument explaining the positioning of the banking institutions draws upon the VAR results discussed previously. Banking institutions are less globally diversified than insurers in terms of CD activities (see Figure 3). The overall concentration of credit risk is thus greater in the banking sector, as it is evident by a larger degree of exposure to subprime instruments for both Lehman Brothers and Citi. Accordingly, specialised and undiversified SIFIs augment systemic risk in the banking sector and consequently are subject to the largest volatility impacts.

AIG and Manulife are, however, notable exceptions and are more involved in the 'non-core' insurance activities compared to the insurance companies least affected by volatility shocks. AIG and Manulife are consequently subject to greater impacts of volatility transmission due to their exposure to credit derivatives instruments.

More generally, our findings clearly suggest that the US institutions as a group appear to be the major 'receiver' of CDS volatility in contemporaneous time and thus they actually pose greater systemic risk. Obviously, future research is needed to further investigate the issue.

\section{Conclusion}

This paper represents an attempt to understand some of the aspects of the potential relationship between the CDS index market and the banking and insurance sector. For this we focus on default risk as perceived by the market through SIFIs share prices.

This paper contributes to the rapidly growing literature on CDs through establishing an empirical relationship between CDS index markets and the equity value of a group of 
SIFIs. A multivariate VAR approach enabled a verification of the linkages between the SIFIs and the CDX and iTraxx investment grade CDS indices.

The results from the Granger causality test show a strong connection between the CDS indices. In particular, we uncover a leading role in terms of pricing discovery for the five year investment grade CDX since with respect to the five year investment grade iTraxx Europe. Although markets are normally inclined to follow the 'random walk', our empirical analysis demonstrates arbitrage opportunities may exist for market participants with the resources to take positions in a timely manner. Arbitrage opportunities however, are likely to disappear very quickly as efficient markets adjust spreads back to equilibrium.

Moreover, we find that the equity returns of all the SIFIs are significantly negatively related to changes in the CDX and iTraxx indices. Taken together, our empirical results show that large shocks in the CDS index market can substantially destabilise the financial system since all of the thirty SIFIs are prone to significant impacts.

Quite strikingly, our empirical evidence uncovers a strong association of negative sign between the geographical location of a SIFI and shocks in the corresponding CDS index market. Accordingly, the iTraxx exhibits a more dominant effect on all European institutions selected in the study, whilst the CDX demonstrates a larger impact on the US institutions. These results are somewhat surprising and their economic importance is significant. For instance, they seem to tell us that globalisation has a neutral impact on international diversification activities. However, remarkably a larger 'non-dominant' index impact on the insurers suggests the insurance sector is diversifying its activities on both sides of the Atlantic at a faster pace than the banking sector. Furthermore, the sector's higher global CDS ratios suggest insurers are less inclined to disrupt financial stability (with the exceptions of AXA and Prudential), since only a global financial meltdown can disrupt operations. In contrast, domestic events can subsequently put a strain on a nation's financial system due to the relative rigidity of the banking sector.

We utilise a GARCH model to establish volatility transmission effects from credit markets into the systematically important institutions share prices. One particular intriguing result of our analysis is that the volatility of the SIFIs equity returns are highly positively related to the volatility of the CDX and iTraxx indices. Thus, as CDS markets become more volatile, then the conditional volatility of the stock market values of all the SIFIs deteriorate. This argues that systemic risk may arise largely through the global financial system. This result is also in line with previous empirical findings by Ang and Longstaff (2013). 
The extent institutions participate in 'core banking activities' considerably influence the length and size of volatility clusters. Moreover, international diversification displays a significant linkage with the volatility transmission mechanism. Another intriguing pattern is that the majority of banks and insurers included in the study reveal a reduced volatility impact when diversifying into international markets. Since the insurance sector is more diversified, the volatility transmission from CDS index markets is less of a concern during the period covered by this study. However, all institutions with high exposure to US subprime instruments are adversely affected.

The findings of the paper identify a challenge for financial regulation. In particular, they highlight at least two important implications for an effective regulation of these institutions.

To begin with, institutions can benefit significantly through diversifying CDS exposure globally, in contrast to merely a specified region. Banks and insurers over-exposed to US subprime mortgages suffered considerably higher equity return reductions, in comparison to the more diverse institutions. Moreover, the contagion effect sent shockwaves throughout the industry and thus, severely disputed financial stability.

Moreover, a larger emphasis on regulation in the insurance sector is essential to discouraging insurers from practices aimed at taking on excessive risk. As the convergence between insurance and banking accelerates, integrated regulation is an essential macroprudential requirement to ensure the risk associated with 'non-core' insurance activities is managed prudently. Furthermore, new players are urged to better understand the potential implications of CRT to enhance survivability during times of severe stress.

Overall, this paper widens the scope for further research on CDS markets. Investigating market correlations with speculative grade corporate entities and other market participants (such as hedge funds) will enhance the understanding of shocks and volatility transfer between markets. Furthermore, future work exploring the potential issue of non-linear dependence between the indices and their relation with equity returns will greatly complement the findings of this study.

The results in this paper have many important implications for financial stability. Clearly, future work is needed to understand the deep reasons for the strong relation between corporate credit risk markets and SIFIs. 


\section{References}

Allen, F. \& Gale, D. (2004). Financial Fragility, Liquidity, and Asset Prices, Journal of the European Economic Association, Issue. 2, pp. 1015-1048.

Allen F., Carletti E., (2006), Credit Risk Transfer and Contagion, Journal of Monetary Economics, No. 53, pp. 80-111.

Ang, A. and Longstaff, F.A. (2013), Systemic Sovereign Credit Risk: Lessons from the U.S. and Europe, Journal of Monetary Economics, 60 (5), 493-510.

Basel Committee on Banking Supervision, (November 2011), Global Systemically Important Banks: Assessment Methodology and the Additional Loss Absorbency Requirement, Bank for International Settlements.

Borio, C., (2003), Towards a Macroprudential Framework for Financial Supervision and Regulation, BIS Working Papers, No. 128.

Brunnermeier, M. K. (2008), Deciphering the 2007-08 Liquidity and Credit Crunch, Journal of Economic Perspectives, Vol. 23, No. 1. pp. 79 \& 82-85.

Calice, G., Ioannidis, C., (2012), An Empirical Analysis of the Impact of the Credit Default Swap Index Market on Large Complex Financial Institutions, International Review of Financial Analysis, 25, 117-130.

Chari V. V., Kehoe P., McGrattan E., (2005), A Critique of Structural VARs Using Real Business Cycle Theory, Federal Reserve of Minneapolis Research Department, Working Paper No. 631.

Choudhary, M. \& Landuyt, G. (2010), Regulating Bank Systemic Risk: New Principles in Macroprudential Management, Global Journal of Management and Business Research, Vol. 10, Issue. 1, pp. $88 . \& 89$.

Čihák, M. (2006), How do Central Banks Write on Financial Stability?” IMF Working Paper, No. 06/163, pp. 9.

De Marzo P., (2005), The Pooling and Tranching of Securities: A Model of Informed Intermediation, Review of Financial Studies, 2005, 18, 1-35. 
Diebold, F.X. and Yilmaz, K. (2014), On the Network Topology of Variance Decompositions: Measuring the Connectedness of Financial Firms, Journal of Econometrics, forthcoming.

Duffie, D. (2008), Innovations in Credit Risk Transfer: Implications for Financial stability, BIS Working Paper, No. 255, pp. 25-29.

Financial Stability Board, (November 2011), "List of Systemically Important Financial Institutions", Bank for International Settlements.

Gorton, G. (2009), The Subprime Panic, European Financial Management, 15(1), pp. 10-46.

International Association of Insurance Supervisors, (July 2013), Global Systemically Important Insurers: Initial Assessment Methodology.

Koop G. Pesaran M. H., Potter S. M., (1996), Impulse Response Analysis in Nonlinear Multivariate Models, Journal of Econometrics, 74: 119-147.

Lee, W. Y., Jiang, C. X. \& Indro, D. C., (2002), Stock Market Volatility, Excess Returns and the Role of Investor Sentiment. Journal of Banking and Finance, Vol. 26, No. 12, pp. 22782281.

Longstaff F. A., (2010), The Subprime Credit Crisis and Contagion in Financial Markets, Journal of Financial Economics, No. 97, pp. 436-450.

Pesaran, M. H. \& Shin, Y. (1998), Generalised Impulse Response Analysis in Linear Multivariate Models, Economics Letters, No. 58, pp. 17-20.

Segoviano, M. and Goodhart, C. (2009), Banking Stability Measures, IMF Working Paper $09 / 04$.

Sims, C. A., (1980), Macroeconomics and Reality, Econometrica, Vol. 48, No 1, pp. 1-48.

Sims, C. A. (1992), Interpreting the Macroeconomic Time Series Facts: The Effects of Monetary Policy, European Economic Review, No. 36, pp. 975-976.

Standard and Poor's, Sovereign Credit Rating List, [Online], Available: http://www.standardandpoors.com/ratings/sovereigns/ratings-list/en/us/?subSectorC ode=39, [Accessed: 29 July 2011]. 
Stock, J. \& Watson, M. (1999), Forecasting Inflation, Journal of Monetary Economics, Edition.

Yang, Jian, and Yinggang Zhou. "Credit Risk Spillovers among Financial Institutions around the Global Credit Crisis: Firm-Level Evidence," Management Science, Vol. 59, No. 10, October 2013, pp. 2343-2359. 